\title{
Semi-synthesis and Anti-Herpetic Activity of New Riolozatrione Derivatives
}

Yolanda D. Estrada-Chavarría, David Silva-Mares, Ernesto Torres-López, Tannya Rocío Ibarra-Rivera and Verónica Mayela Rivas Galindo

Universidad Autónoma de Nuevo León, Facultad de Medicina, Dept. Quimica Analitica San Nicolás, 64841, NL, México.

\begin{abstract}
Riolozatrione is a natural diterpene isolated from Jatropha dioica to which antiherpetic activity is attributed. Riolozatrione possess a unique diterpene core attractive for chemical modification. In this work, 5 new derivatives were obtained by chemical reduction and cyclopropane ring-opening. NMR techniques where used for the structural characterization. One and two-dimension NMR experiments (COSY, $\mathrm{HMBC}, \mathrm{HSQC}$, and NOE) confirm the structures of 5 new riolozatrione derivatives. Anti-herpetic activity was improved by chemical modification in some derivatives.
\end{abstract}

Keywords: Riolozatrione, structural modification, anti-herpetic activity

\section{INTRODUCTION}

Diterpenes occurring in Euphorbiaceae family are an especial group of structurally diverse natural products with significant biological properties. ${ }^{1-2}$ In the genus Jatropha (Euphorbiaceae), diterpenes are the predominant constituents and without exception own varied biological activities. ${ }^{3-4}$ Native to México, Jatropha dioica ("Sangre de Drago") 5 has been investigated for phytochemical content. Earlier studies on the roots of J. dioica, lead to the identification of three diterpenes: jatropholone $B{ }^{6}$ citlalitrione $^{7}$ and riolozatriona ${ }^{8}$ and a bio-guided fractionation of anti-herpetic compounds lead to Riolozatrione. ${ }^{9}$ To best our understanding, riolozatrione possess a unique skeleton not found in other species. On the basis of these uncommon structural features, our research focuses on the chemical modification of Riolozatrione in order to explore its chemistry and improve its anti-herpetic activity.

In view of this, we report our results in the synthesis of 5 new derivatives of riolozatriona via chemical modification ${ }^{10-11}$ such as hydrogenation, cyclopropane ringopening and borohydride ketone-reduction. Anti-herpetic and cytotoxic activities are also described.

\section{RESULTS AND DISCUSSION}

Riolozatrione was isolated and purified according our previous reported methodology. With 1 gram of purified Riolozatrione three chemical reactions were performed to modify $\alpha, \beta$-unsaturated ketone, 1,1-dimethylcyclopropane and 1,3diclyclohexadienone functional groups (Scheme 1). Five different semi-synthetic derivatives were obtained and evaluated to detect any change in activity during antiherpetic and cytotoxic assays. 

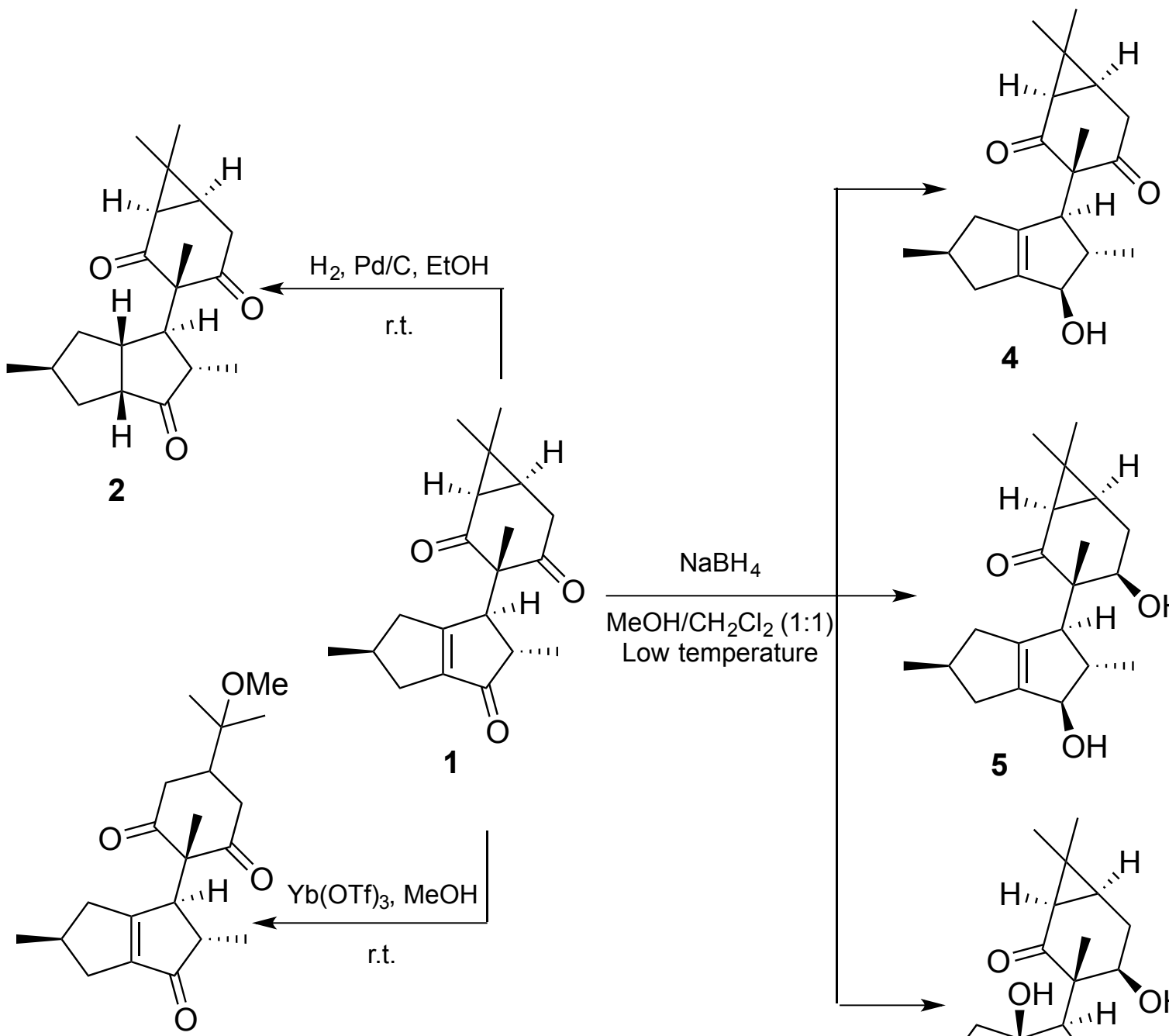

3

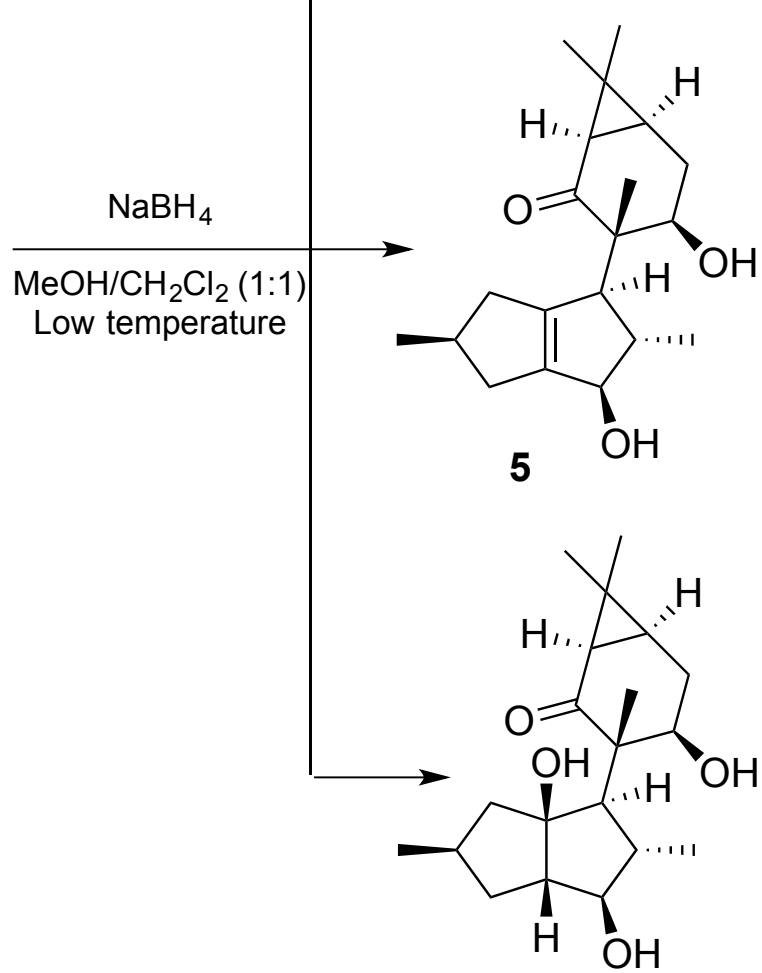

6

Following a classical procedure ${ }^{12}$ riolozatrione $\mathbf{1}$ was added to a suspension of palladium on carbon in ethanol and hydrogenated to provide in quantitative yield compound 2, which result from selective reduction in double bond of $\alpha, \beta$-unsaturated ketone. Next, 1,1-dimethylcyclopropane of riolozatrione was regioselective opened with methanol and ytterbium trifluoromethane sulfonate $\mathrm{Yb}(\mathrm{OTf})_{3}{ }^{13}$ to give in low yield (20\%) derivative 3, as single product isolated. According literature, this reaction proceeds with mild Lewis acid in low yields to avoid by products. ${ }^{14}$ Finally, in the sodium borohydride reduction to reduce selectively the ciclohexadienone carbonyls we essayed methanol/diclorothane and low temperature. ${ }^{15}$ Derivatives 4-6 were isolated and identified from crude mixture in moderate to low yields (40-20\%) of the purified compounds. Surprisingly, one of the two carbonyls of 1,3-cyclohexadienone was not reduced. It may be sterically hindered to be attack by sodium borohydride. In general, conjugate ketones are less reactive than ketones toward nucleophilic attack of sodium. ${ }^{15}$ However, derivative 4 was found in $30 \%$ yield and so far, the ketone 
reduced derivative has not been recovered. Derivative $\mathbf{5}$ probably arises from ketone reduction of compound $\mathbf{4}$ in low yield (20\%). Mayor component was completely hydroxylated derivative 6, which was obtained in 40\% yield. Most likely compound 6 result from 1,4-addition of water and subsequent sodium borohydride reduction of two ketones. The orientation of new hydroxyl groups is beta. One and two-dimension NMR experiments (COSY, HMBC, HSQC, and NOE) confirm the structures of 5 new riolozatrione derivatives.

The cytotoxicity of new riolozatrione derivatives was studied in Vitro against Vero cells lines (Table 1). Derivatives $\mathbf{3}$ and $\mathbf{4}$ were less cytotoxic whereas Vero cells were more susceptible to compounds $\mathbf{6}$ and $\mathbf{2}$. We speculate that manipulation of ketone and double bound of $\alpha, \beta$-unsaturated is crucial to improve the therapeutic index of riolozatrione. Reduction of double bond will enhance significantly the cytotoxicity. The half maximal inhibitory concentration $\left(\mathrm{IC}_{50}\right)$ against HSV-1, was higher for riolozatrione derivative 2 followed by compound 3. Activity of derivatives $\mathbf{6}$ and $\mathbf{4}$ was low compared with riolozatrione.

Base on selectivity index (SI), an important parameter for evaluating antiviral activity, ${ }^{17}$ the reduction of one carbonyl group in 1,3-cyclohexadienone, and the hydroxylation of the double bond in compound $\mathbf{6}$, significantly decreases the antiviral activity. The reduction of carbonyl of conjugate ketone increase slightly the activity against HSV-1. The reduction of the double bond seems not affect significantly the anti-herpetic activity based on the value of SI retrieved for the compound 2 . Finally, 1,1-dimethyl-cyclopropane seems not be important for the biological activity of riolozatrione, due compound $\mathbf{3}$ gives an important increase antiviral activity.

Table I: Cytotoxic effect against Vero cell line using MTT assay, and anti-herpetic activity of derivatives obtained.

\begin{tabular}{cccc}
\hline Compound & $\begin{array}{c}\text { Vero cells } \\
\mathrm{CC}_{50}, \mu \mathrm{g} / \mathrm{mL}\end{array}$ & $\begin{array}{c}\mathrm{HSV}-1 \\
\mathrm{IC}_{50}, \mu \mathrm{g} / \mathrm{mL}\end{array}$ & $\begin{array}{c}\text { SI } \\
\mathrm{CC}_{50} / \mathrm{IC}_{50}\end{array}$ \\
\hline 1 & $384 \pm 1.9^{\mathrm{a}}$ & $66 \pm 8.6^{\mathrm{b}}$ & 5.8 \\
2 & $102 \pm 10.1^{\mathrm{a}}$ & $23.65 \pm 1.2^{\mathrm{b}}$ & 4.3 \\
3 & $>1600$ & $147 \pm 6.3^{\mathrm{b}}$ & 10.8 \\
4 & $1624 \pm 5.1^{\mathrm{a}}$ & $222 \pm 11.8^{\mathrm{b}}$ & 7.3 \\
5 & $\mathrm{ND}$ & $\mathrm{ND}$ & $\mathrm{ND}$ \\
6 & $718 \pm 66.8^{\mathrm{a}}$ & $>500$ & 1.4 \\
\hline
\end{tabular}

$\mathrm{a}=$ data expressed as the mean value of $\mathrm{CC}_{50}(\mu \mathrm{g} / \mathrm{mL}) \pm \mathrm{S} D, \mathrm{n}=3$. $\mathrm{b}=$ data expressed as the mean value of $\mathrm{IC}_{50}(\mu \mathrm{g} / \mathrm{mL}) \pm \mathrm{S} . \mathrm{D}, \mathrm{n}=3$.

$\mathrm{ND}=$ Not determined 
General Experimental Procedures. The 1D and 2D NMR experiments were performed on a Bruker Avance III HD at $400 \mathrm{MHz}$ for ${ }^{1} \mathrm{H}$ and $100 \mathrm{MHz}$ for ${ }^{13} \mathrm{C}$. Chemical shifts were referenced to TMS, and $J$ values are given in Hz. The EIMS data were recorded on an Agilent Technologies 6890N Chromatograph that was coupled to the selective mass spectrometer 5973 INERT. Silica gel 0.04-0.063 $\mu \mathrm{m}$ (Aldrich) and LiChroprep RP-18 40-63 $\mu \mathrm{m}$ (Merck) were used for column chromatography. TLC was carried out on silica gel $60 \mathrm{~F}_{254}$ (Merck).

Cell Culture and Viral Particles. Mammalian Vero cells were used for the cytotoxicity and antiviral assays. Cells were grown in advanced DMEM media that was supplemented with $2 \%$ fetal bovine serum with glutamine, essential amino acids, streptomycin and $1 \%$ penicillin. Cells were maintained at $37{ }^{\circ} \mathrm{C}$ in a $5 \% \mathrm{CO}_{2}$ atmosphere to reach $80 \%-90 \%$ confluence. HSV-1 was obtained from a clinical isolate of an infected patient at the Department of Dermatology, UANL. The isolate was found to be positive for the herpes simplex virus thymidine kinase gene by the polymerase chain reaction (PCR) assay and positive for the cytopathic effect of HSV infection by Vero cell culture.

Cytotoxicity Assay. Cell viability was determined according to the MTT method. ${ }^{14}$ Compounds were further examined for toxicity in a Vero cell line at concentrations of 100, $250,500,1000$ and $2000 \mu \mathrm{g} / \mathrm{mL}$. After 3 days of incubation, cell viability was assessed by adding $10 \mu \mathrm{L}$ of a solution of $5 \mu \mathrm{mg} / \mathrm{mL}$ of 3-(4,5-dimethylthiazol-2-yl)-2,5diphenyltetrazolium bromide (MTT). The $\mathrm{CC}_{50}$ was determined as the concentration of the compound required to reduce cell viability by $50 \%$, taking as much as $100 \%$ of the untreated cells. The experiments were performed in triplicate for each compound.

Anti-herpetic Assay. The anti-herpetic effect on HSV-1 in vitro was evaluated using the reduction plaque assay. ${ }^{15}$ Briefly, $5 \times 10^{5}$ Vero cells were seeded onto six-well culture plates and then incubated with 100 plaque forming units (PFU) of HSV-1 or HSV-2 for $1 \mathrm{~h}$ at $37{ }^{\circ} \mathrm{C}$. Supernatant was discarded, and fresh medium was supplemented with $1 \%$ DMSO, and $0.32 \%$ IgG was added. Concentrations of 80,160 and $320 \mu \mathrm{M}$ of each compound were tested. Cells were incubated for $72 \mathrm{~h}$ for HSV-1 and HSV-2. Finally, the cells were fixed with methanol and stained with Giemsa reagent. Negative (MOCK) and positive (Acyclovir, ACV) controls were used for each assay. All assays were carried out in triplicate.

\section{CONCLUSIONS}

In conclusion, the results of this study revealed that preliminary chemical modifications can enhance the anti-herpetic activity of riolozatrione. According biological evaluation, most likely the $\alpha, \beta$-unsaturated cyclopentenone is the most important structural motif in riolozatrione. Selective sodium borohydride reduction are highly demanded.

\section{ACKNOWLEDGMENTS}

This work was supported by a grant from the CONACYT $(252589$, 2015). EstradaEcheverria is grateful to CONACYT for their fellowship. 


\section{AUTHOR CONTRIBUTIONS}

Estrada-Chavarria isolate Riolozatriona (1) synthesized compounds (2-6). Silva-Mares realized the biological evaluation, which where made in the laboratory of Torres-López who also supervised the biological experiments. Rivas-Galindo participated in structural elucidation of all new compounds. Ibarra-Rivera directed the synthetic methodology used. Both, Rivas-Galindo and Ibarra-Rivera are the responsible researcher and Ibarra-Rivera to whom correspondence must be addressed. Authors contributed equally to this work.

CONFLICTS OF INTEREST

The authors declare no conflict of interest.

\section{REFERENCES}

1. Vasas, A., Redei, D., Csupor, D., Molnar, J., Hohmann, J. Eur. J. Or. Chem. 2012, 51155130.

2. Vasas, A. and Hohmann, J. Chem. Rev. 2014,114, 8579-8612.

3. Sharma, S. and Singh, H. Chin. J. Integr. Med. 2012, 18, 868-880.

4.Devappa, R., Makkar, H., Becker, K. J. Am. Oil Chem. Soc. 2011, 88, 301-322.

5. Traditionally used in herbal medicine to cure the toothache and some ulcer.

6. Pertino, M., Schmeda-Hirschmann, M., Rodriguez, J.A., Theoduloz, C. Planta Med. 2007, 73, 1095-1100.

7. Dominguez, X., Villareal A. M. J. Nat. Prod. 1988, 51, 749-753.

8. Dominguez, X., Cano, G., Franco, R., Villareal, A.M., Watson, W.H., Zabel, V. Phytochemistry 1980, 19, 2478.

9. Silva-Mares, D., Torres-Lopez, E., Rivas-Estilla, A.M., Cordero-Perez, P., WaksmanMinsky, N., Rivas-Galindo, V.M. Nat. Prod. Comm. 2013, 8, 297-298.

10. It is widespread in literature that chemical modification is an effective strategy in drug discovery to upgrade pharmacological properties of poorly active natural products.

11. Li-Gand, U., Teng-Feng, N., Wei, G., Yuan, H., Ying-Ying, W., Hai-Wei, C., Gai-Gaung, Y. and Wen-Wei, Q. Eur. J. Med. Chem. 2015, 90, 10-20.

12. Tian, S., Lu, S. Synlett, 2004, 1953-1956.

13. Kobayashi, S. Synlett 1994, 689-701.

14. Appendino, G., Tron, G.C., Jarevang, T., Sterner, O. Org. Lett. 2001, 3, 1609-1612.

15. Ward, D.E., Rhee, C. Can. J. Chem. 1989, 67, 1206-1211.

16. The relative effectiveness of the investigational product in inhibiting viral replication compared to inducing cell death is defined as the therapeutic or selectivity index (i.e., $\mathrm{CC}_{50}$ value/EC50 value). It is desirable to have a high therapeutic index giving maximum antiviral activity with minimal cell toxicity. FDA Guidance for industry 2006.

17.Cos, P., Vlietinck, A., Vanden Berghe, D., Maes, L. J. Of Etnopharmacology 2006, 106, 290-302. 